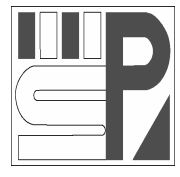

Science Press
Journal of Arid Land

2012, 4(2): 132-139

doi: 10.3724/SP.J.1227.2012.00132

jal.xjegi.com; www.chinasciencejournal.com

\title{
Effects of irrigation on precipitation in the arid regions of Xinjiang, China
}

\author{
Yong $\mathrm{ZHAO}^{1 *}$, YongJie $\mathrm{FANG}^{2}$, CaiXia $\mathrm{CUI}^{3}$, AnNing $\mathrm{HUANG}^{4}$ \\ ${ }^{1}$ Institute of Desert Meteorology, China Meteorology Administration, Urumqi 830002, China; \\ ${ }^{2}$ Beijing Climate Center, China Meteorological Administration, Beijing 100081, China; \\ ${ }^{3}$ Xinjiang Meteorological Observatory, Urumqi 830002, China; \\ ${ }^{4}$ School of Atmospheric Sciences, Nanjing University, Nanjing 210093, China
}

\begin{abstract}
Soil moisture is an important parameter for the interaction between soil and atmosphere. It is the second important factor that influences climate change, next to sea surface temperature (SST). Most previous studies focused on the monsoon regions in East China, and only a few laid emphases on arid environments. In Xinjiang, which is located in Northwest China, the climate is typically arid and semi-arid. During the past 20 years, the precipitation in Xinjiang has shown a significant increasing trend, and it is closely related to oasis irrigation. This paper aims at discussing whether abnormal soil moisture in spring can be the signal to forecast summer precipitation. The effects of abnormal soil moisture due to farm irrigation in spring in arid environments on regional climate are investigated by using a regional climate model (RegCM3). The results indicate that positive soil moisture anomaly in irrigated cropland surface in May led to an increase in precipitation in spring as well as across the whole summer. The impact could last for about four months. The effects of soil moisture on the surface air temperature showed a time-lagging trend. The summer air temperature declined by a maximum amplitude of $0.8^{\circ} \mathrm{C}$. The increased soil moisture could enhance evaporation and ascending motion in the low troposphere, which brought in more precipitation. The soil moisture affected regional weather and climate mainly by altering the surface sensible and latent heat fluxes.
\end{abstract}

Keywords: irrigation; abnormal soil moisture; weather and climate effects; precipitation; arid region; Xinjiang

As one of the important parameters for land surface process, soil moisture plays an important role in regional weather and climate change by affecting the heat fluxes at the interface between atmosphere and land (Walker et al., 1977; Ma et al., 2001). The study of Global Ocean-Atmosphere-Land System (Barron, 1994) shows that the function of soil moisture is the second important parameter next to sea surface temperature (SST) for climate change. The continuity of abnormal climate in China is highly related to soil moisture status (Guo et al., 2003; Sun et al., 2005; Xie et al., 2005). Due to the lack of observed soil moisture data and biases and uncertainties in the National Center for Environmental Prediction/National Center for Atmospheric Research (NCEP/NCAR) reanalysis (Roads et al., 1999; Lenters et al., 2000), previous studies about the impact of soil moisture on weather and climate change mainly concentrate on numerical simulation. Namias $(1958,1963)$ found that the seasonal abnormality of soil moisture is of great importance in affecting the seasonal changes of atmosphere. Henderson-Sellers (1996) revealed that $65 \%$ of the precipitation on the land is from land evaporation (the other $35 \%$ is from the ocean's water vapor transportation), indicating that the precipitation on land is mainly from land surface evaporation closely related to soil moisture. Comparsion of the model results from experiments with dry and moist soils (Shukla and Mintz, 1982) showed that dry soils receive rainfalls about $40 \%-50 \%$ less than moist soils in July in most

Received 2011-09-14; accepted 2011-12-26

*Corresponding author: Yong ZHAO (E-mail: zhaoyong@idm.cn) 
parts of land or non-monsoon regions, signifying that land evaporation is a very important source for land precipitation. Numerical experiments display that the climate abnormality resulting from soil irrigation can last around 3-5 months and even longer in the midand high-latitude regions. However, precipitation has dramatically decreased over the non-monsoon regions in the western part of China where the soil is dry (Yeh et al., 1984; Zhu et al., 1996). Influence of abnormal soil moisture on climate changes, by using IAP (Institute of Atmospheric Physics, Chinese Academy of Sciences) atmospheric circulation model, revealed that the positive abnormality of soil moisture can strengthen precipitation (Wang, 1991). In addition, Li et al. (2007) conducted a numerical study on the regional climate effect induced by the soil moisture abnormality in spring across Yangtze-Huaihe river valleys and found that the variation of soil moisture drastically affected regional precipitation.

Previous studies based on observations indicated that a noticeable trend of "warming and humidification" with obviously increasing precipitation in Xinjiang has appeared since the late 1980s (Shi et al., 2002; He et al., 2003). Yang and Zhang (2007) suggested that the precipitation increase in Xinjiang is correlated to the unusual atmospheric circulation which presents with the equivalent barotropic structure as well as the active low-value system in Central Asia. However, other researchers argued that the increasing precipitation in Xinjiang is closely related to the increase in oasis area and farm irrigation (Zhang and Shi, 2002). As well known, irrigation can not only change soil moisture, but also significantly alter hydrologic cycle and energy budget at the interface between atmosphere and land, further affecting local climate. However, the effects of irrigation on precipitation remain equivocal. Some researchers argued that large-scale irrigation can lead to an increase in precipitation (Eddy et al., 1975; Barnston and Schickedanz, 1984; DeAngelis et al., 2010), but others pointed out that no evidences can prove the significant effects of irrigation on precipitation (Eddy et al., 1975; Moore and Rojstaczer, 2001). Therefore, whether or not irrigation can induce precipitation increase in Xinjiang is still an unsolved problem. However, some work has been done to reveal the relationship between irrigation and precipitation in Xinjiang. Irrigation farming is commonly practised in most oases in Xinjiang, which makes it a typical area for studying the influences of irrigation on regional weather and climate. The aim of this study is to investigate the relationship between spring irrigation and summer precipitation and further explore the possible physical mechanisms behind.

\section{Model and experimental design}

The regional climate model used in this study is RegCM3, which was developed in Abdus Salam International Centre for Theoretical Physics (ICTP). RegCM3 is a hydrostatic model based on the fifthgeneration Pennsylvania State University-National Center for Atmospheric Research Mesoscale Model (PSU-NCAR/MM5) (Grell et al., 1994). In this study, the radiative transfer package of National Center for Atmospheric Research (NCAR) Community Climate Model version 3 (CCM3) (Kiehl et al., 1996) was employed; the non-local atmospheric boundary scheme developed by Holtslag (1990) was adopted; the Grell cumulus convective parameterization scheme was used; and the Subgrid Explicit Moisture Scheme (SUBEX) (Pal et al., 2000) was applied to treat non-convective cloud and precipitation processes. Model domain in this study includes the entire Xinjiang and its surrounding areas (Fig. 1). The domain center is $84.5^{\circ} \mathrm{E}, 41.5^{\circ} \mathrm{N}$ and the grid is $78 \times 70$ with a grid spacing of $30 \mathrm{~km}$. RegCM3 has 18 vertical levels with sigma coordinates and the model top is at $10 \mathrm{hPa}$. Exponential Relaxation Method (Davies and Turner, 1977) was used for the model lateral boundary with 12 grids in the butter zone. The initial and lateral boundary conditions were derived from National Center for Environmental Prediction/Department of Energy (NCEP/ DOE) reanalysis 2 (R2) (Kanamitsu et al., 2002) and updated every 6 hours.

Irrigation farming areas in Xinjiang are selected as key regions to explore the impact of the soil moisture abnormality caused by spring irrigation on the regional weather and climate in summer. The land types/vegetations were divided into 20 categories in the land surface scheme (BATS1E), of which Category 10 is irrigated crop (Fig. 1). In order to study the effects with Category 10, the soil moisture of 1 May, 
1996 was used for a 6-month control and sensitivity integration (from 1 April to 30 September, 1996). During the sensitivity experiment, the soil moisture value at 0:00 of 1 May is changed into abnormal value after one month's spin-up time. There are three vertical layers of soil moisture in the model and the abnormal values of regional soil moisture from the top layer to the deep layer increased by $60 \%, 40 \%$ and $20 \%$, respectively, relative to the original values in the control experiment.

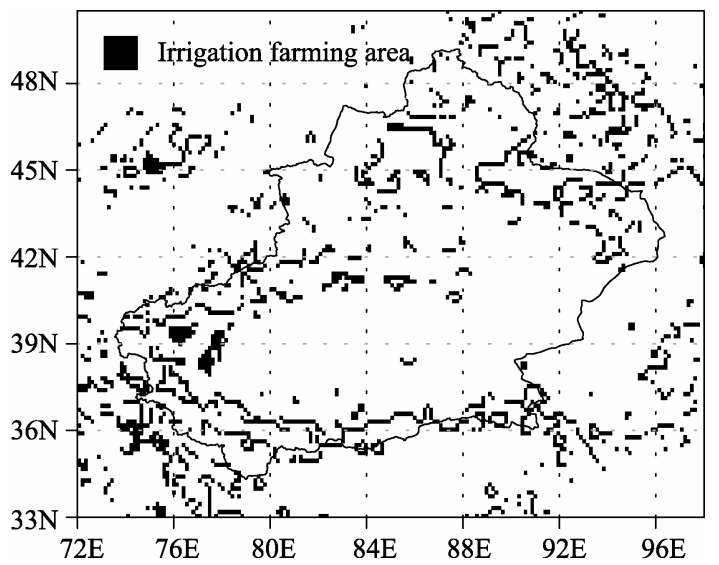

Fig. 1 Simulation region and the distribution of irrigation farming area
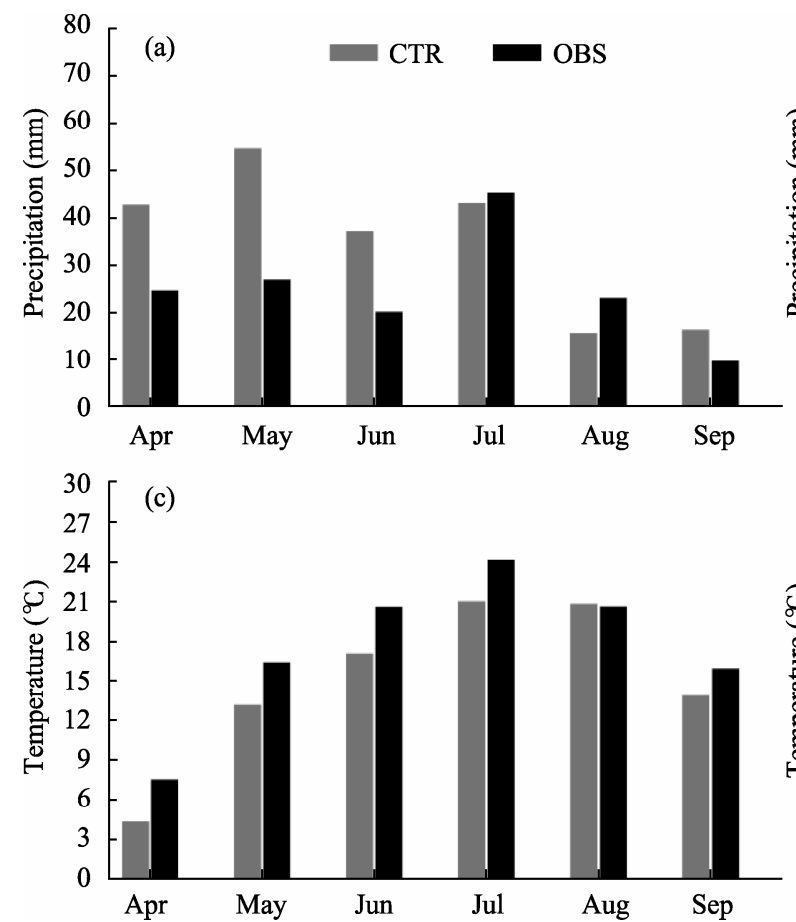

\section{Results}

\subsection{Distributions of the difference values of pre- cipitation and temperature}

Comparison between the precipitation and surface temperature simulated from the control experiment with observed values shows that RegCM3 well reproduces the monthly variation of precipitation in South and North Xinjiang (Fig. 2), despite that the precipitation intensity is overestimated. The model can well simulate the monthly variation of temperature as well but with cold biases. These results disagree with those obtained in the monsoon areas in East China (Li et al., 2007). Meanwhile, RegCM3 has better performance in simulating the precipitation and land surface temperature in North than in South Xinjiang. Overall, RegCM3 can properly simulate the precipitation and land surface temperature.

Figure 3 shows the monthly rainfall difference between sensitivity and control experiments. Soil moisture abnormality resulted in large precipitation differences between both sides of the western part of Tianshan Mountains. The precipitation differences varied obviously during the first 4 months and became very small in September, indicating that the effect of soil mois-
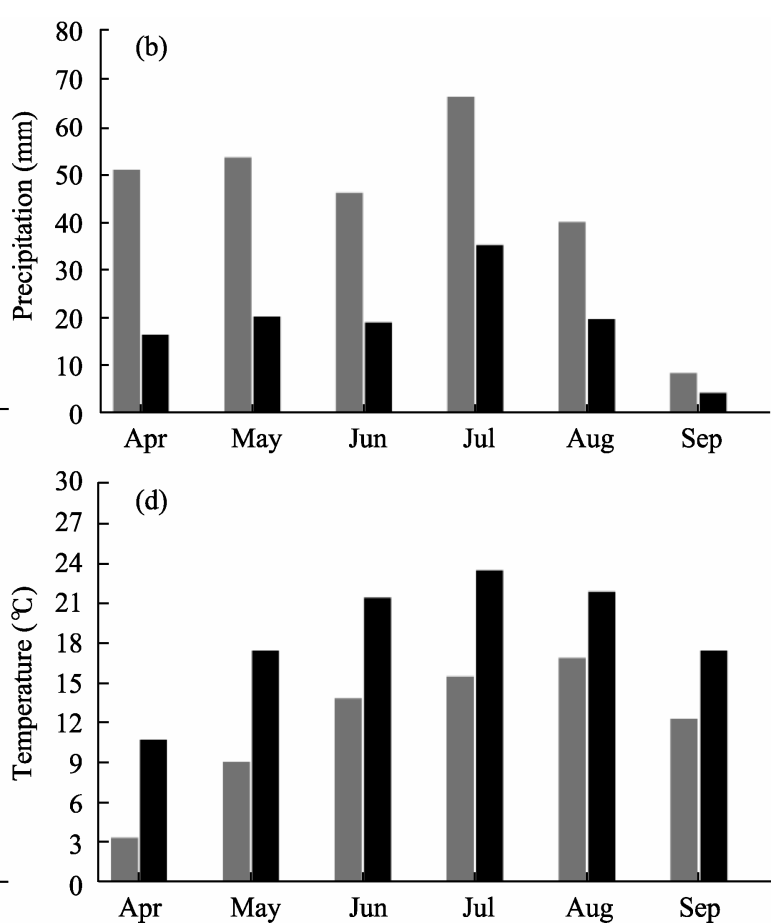

Fig. 2 The simulated and observed regional mean precipitation and surface temperature in North (a, c) and South (b, d) Xinjiang in 1996; CTR means simulated values and OBS means observed values. 

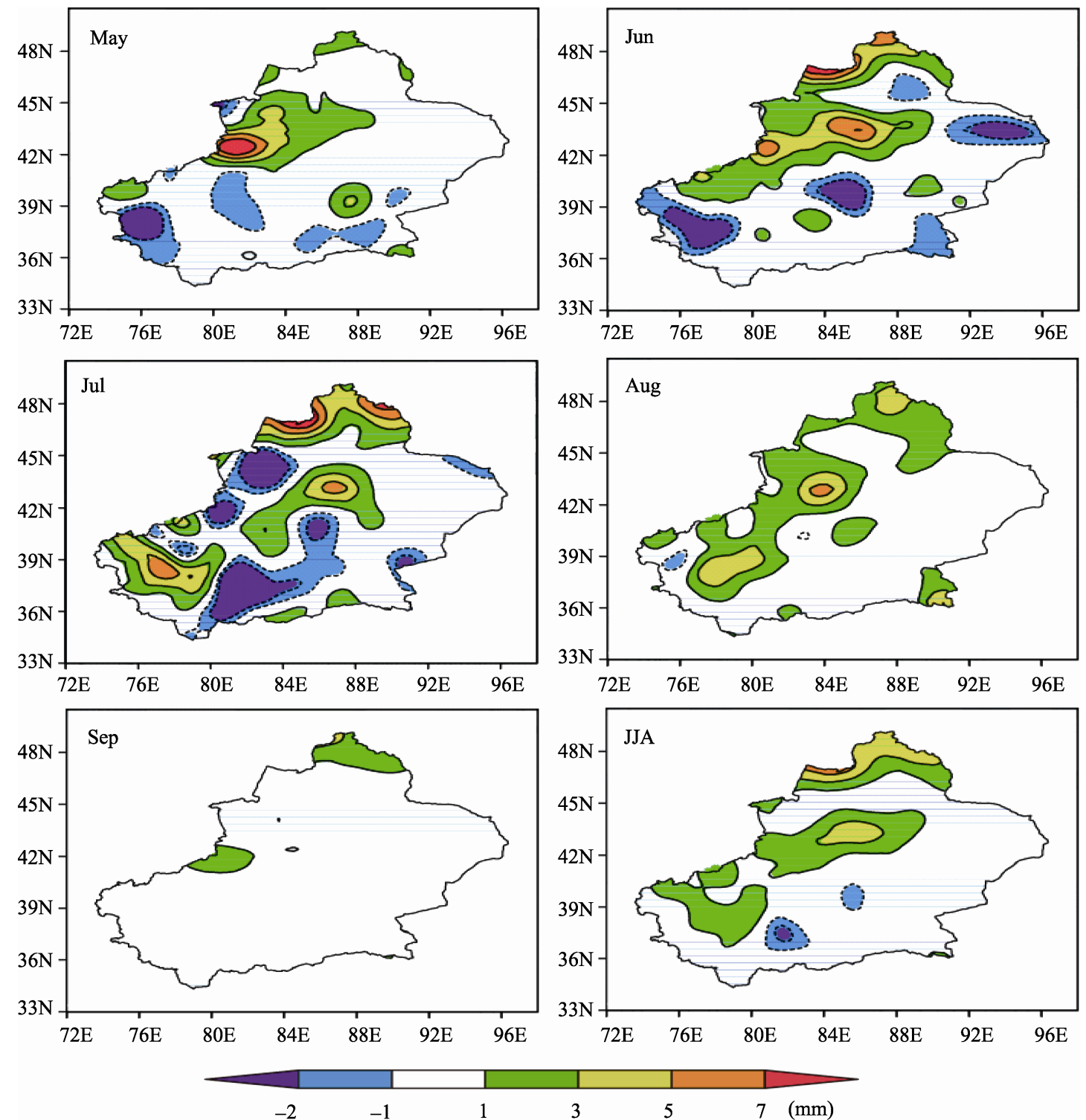

Fig. 3 Precipitation differences between sensitivity and control experiments

ture anomaly declined significantly till almost disappeared. In addition, in the first and second months the differences mainly appeared in North Xinjiang, but starting from the third and fourth months, they extended to the western part of South Xinjiang. The precipitation in North Xinjiang varies with latitudes. The increase in precipitation mainly occurred in the later 4 months after abnormality emerges in the soil moisture. This situation lasted longer in Xinjiang than in the monsoon areas in East Asia. The increased precipitation mostly fell at both south and north of Tianshan Mountains and the western part of South Xinjiang, where the main oasis areas of Xinjiang are present and where evaporation is more strong (data not shown). The precipitation increase during the later period in local or nearby areas mainly responds to the abnormality of soil moisture in oasis areas.

Figure 4 gives the mean temperature difference between the sensitivity experiment and the control experiment. The result indicates that compared to the control experiment the change in air temperature for the sensitivity experiment is very slight with a bit lower (warmer) temperature over the northwestern part of North Xinjiang and parts of South Xinjiang in May. However, compared with the control experiment, the summer mean temperature for the sensitivity ex- 
periment decreases significantly in the oasis areas in North Xinjiang. In areas around Altai and Tacheng prefectures, the temperature can even drop by a maximum amplitude of $0.8^{\circ} \mathrm{C}$. The result is consistent with that from previous observations (Zhang and Shi, 2002). The decrease of soil temperature and the reduction in the conveyance of surface sensible heat, as well as the humidity increase and temperature decrease in the low-level atmosphere, can result in cloud growth and solar radiation weakening, which makes surface temperature and atmosphere temperature decrease, conducing to a further positive feedback.

\subsection{Distribution of difference values of circulations}

The variation of soil moisture can cause changes in the exchanges of water vapor and energy between land and atmosphere, and further alter the temperature and humidity of atmosphere and form anomalous circulations. According to Fig. 5, the anomalous south winds occurred in South Xinjiang in May, and the tempera- tures in this region were also increased. The horizontal wind shear anomaly appeared in the western part of Tianshan Mountains, where the precipitation was also increased. In summer, an anomalous cyclone circulation emerged in the low-level atmosphere over the Tarim Basin. And when the anomalous anticyclone circulation presented a deviation over the northwestern part of North Xinjiang, it became developed. This phenomenon matches with the precipitation increase in these regions. The abnormality of soil moisture in May is prone to induce anomalous cyclone circulations over Xinjiang and its adjacent areas in summer, which also works as a key factor impacting the precipitation in these regions.

Figure 6 shows the zonal-height and meridional-height sections of mean vertical wind speed differences in summer, revealing ascending motion anomaly extending from east to west and from north to south. This is corresponding to the case for the latitudes in oasis concentration areas. Under the heat

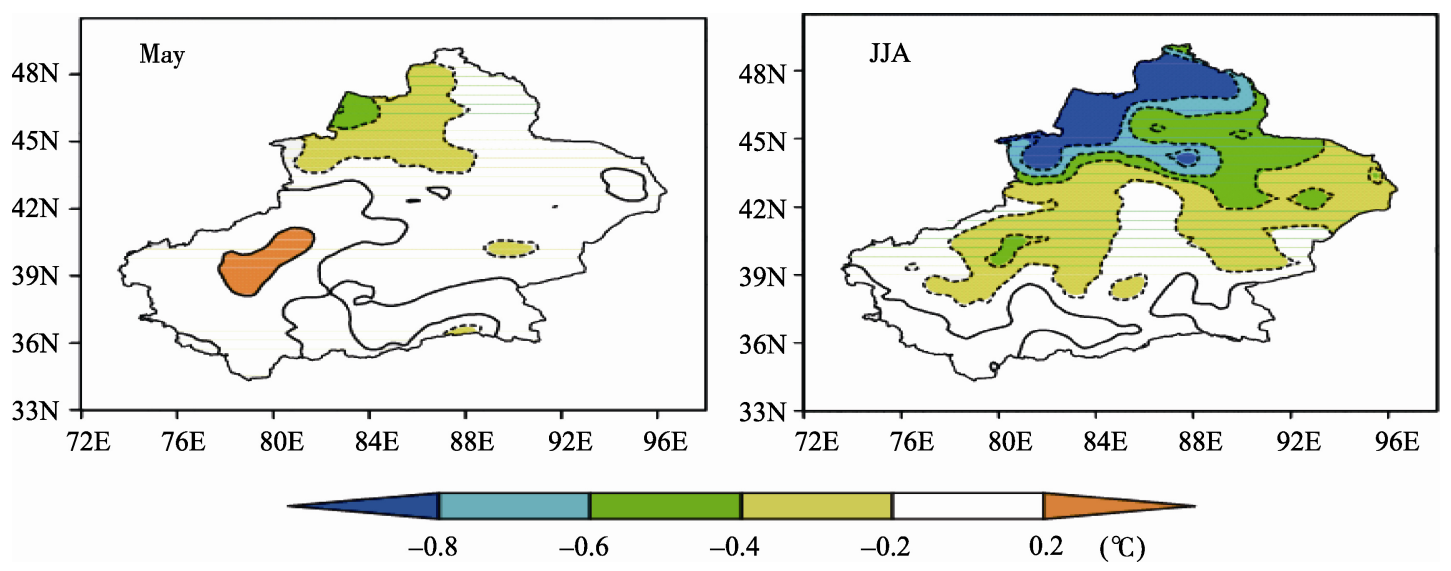

Fig. 4 Air temperature differences between sensitivity and control experiments
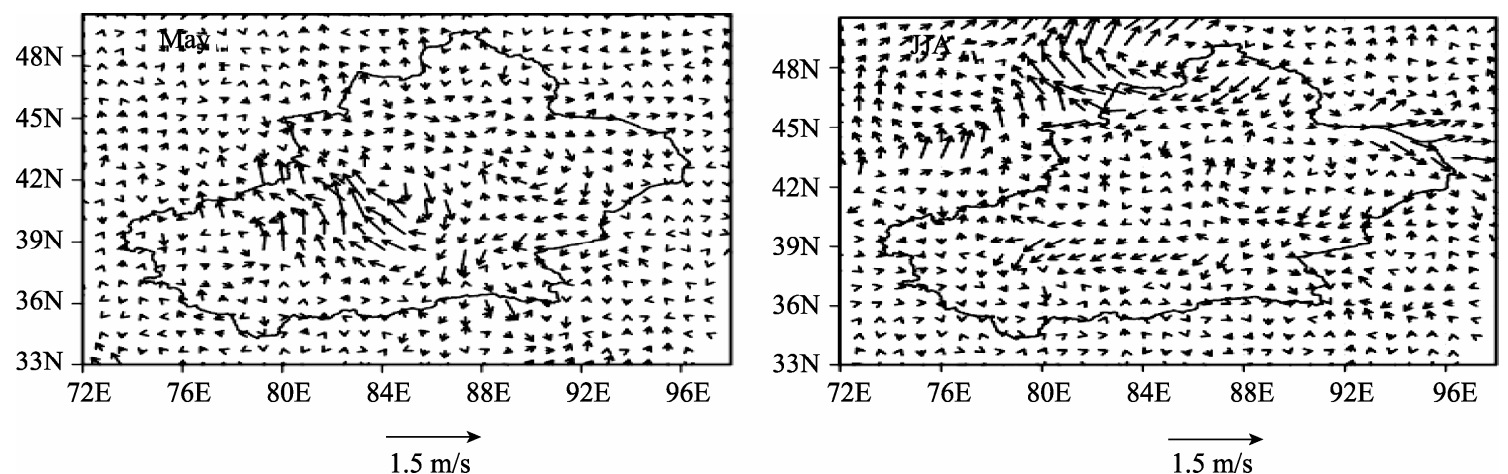

Fig. 5 Difference in wind vector at $850 \mathrm{hPa}$ between sensitivity and control experiments 


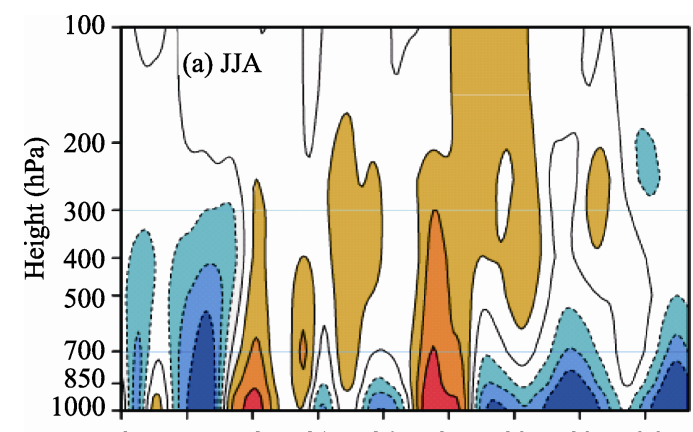

$\begin{array}{lllllllll}72 \mathrm{E} & 75 \mathrm{E} & 78 \mathrm{E} & 81 \mathrm{E} & 84 \mathrm{E} & 87 \mathrm{E} & 90 \mathrm{E} & 93 \mathrm{E} & 96 \mathrm{E}\end{array}$

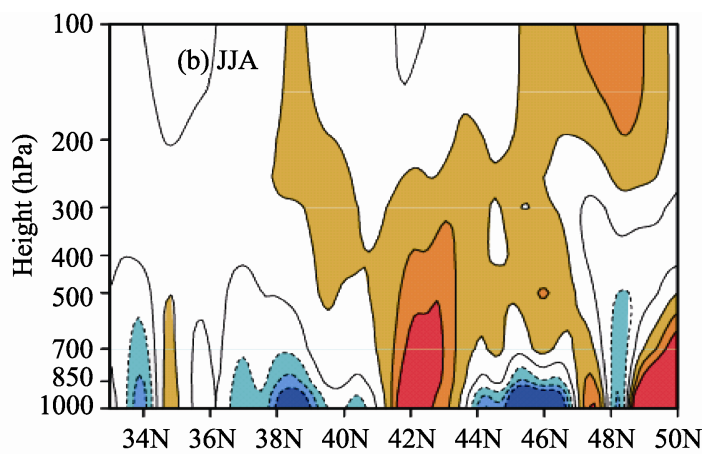

$0.09(\mathrm{~Pa} / \mathrm{s})$

Fig. 6 Zonal-height section (a) and meridional-height section (b) of vertical wind speed differences between sensitivity and control experiments

forcing in summer, the northern side of Tibetan Plateau is dominated by sinking airflows. Therefore, the winds may generate a difference in the ascending speed after soil moisture becomes abnormal and the geopotential heights weaken at $700 \mathrm{hPa}$ or lower levels. Such impacts on geopotential heights are located at much lower levels in East China where vigorous convections often occur in summer. The strengthened ascending motion of atmosphere contributes to favorable conditions for precipitation. The variation of characteristics in regional underlying surface has a significant impact on the intensity of short-term precipitation across our study area. The impact in Xinjiang mainly resulted from changing the energy exchange form of land-atmosphere system and the sublevel circulation formation of heterogeneous surface thermal force, and meanwhile, the impact in the nearby areas is mainly due to the function of sub-level circulation and large-scale stratospheric processes (Du and Yan, 1993).

\subsection{Analysis on energy variation}

The changes of soil moisture contribute to the variation of surface parameters such as albedo, evaporation, the water vapor content of atmosphere, cloud amounts, and changes in the equilibrium relations of land-atmosphere energy exchange. The time evolution of the regional mean difference in the four surface heat flux components, including net downward solar short-wave radiation, net upward long-wave radiation, sensible heat flux and latent heat flux, is shown in Fig. 7. The four surface heat flux components show no differences between the sensitivity experiment and the control experiment in April when no soil moisture abnormality is present, but the changes in the four heat flux components can be noted after the abnormality is input on 1 May. However, the changes in the four heat flux components with the input of the soil moisture abnormality are not significant in May, but significant changes can be observed in summer, making the latent heat flux significantly increase compared to the control experiment. The significant increase is mainly due to increased evaporation. The air temperature in the low-level is mainly affected by the long-wave radiation of the surface. The long-wave radiation is relatively weak and makes the air temperature decline and the surface heat flux decrease. During the process of surface energy balance, the increase in latent heat flux is offset by the decrease in long-wave radiation and sensible heat flux. The short-wave radiation differences are much smaller than those of the other components. The situation over South Xinjiang is very similar to that over North Xinjiang (data not shown).

\section{Discussion and conclusion}

The abnormality of soil moisture exerts significant impacts on regional precipitation and air temperature by changing the surface radiation flux, sensible heat and latent heat fluxes between atmosphere and land. Increased soil moisture can result in an increase in surface evaporation and a decrease in surface temperature by a maximum amplitude of $0.8^{\circ} \mathrm{C}$. After the 


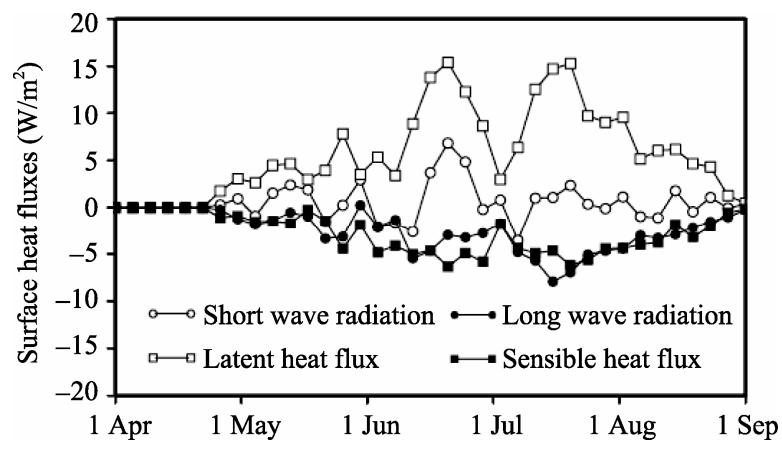

Fig. 7 Time evolution of the regional mean difference in the surface heat fluxes between sensitivity and control experiments over North Xinjiang

soil moisture abnormality was introduced, significant impacts of soil moisture on precipitation and temperature appeared in May and ran through the whole summer. The abnormal increase of soil moisture can produce a circulation system in the low-level wind fields that is propitious to precipitation increase. Meanwhile, the strengthened convective ascending motion pro-

\section{References}

Barnston A G, Schickedanz P T. 1984. The effect of irrigation on warm season precipitation in the Southern Great Plains. Journal of Climate Applied Meteorology, 23(6): 865-888.

Barron E J. 1994. GOALS (Global Ocean-Atmosphere-Land System) for Predicting Seasonal-to-International Climate: A Program of Observation, Modeling, and Analysis. Washington DC: National Academy Press.

Davies H, Turner R. 1977. Updating precipitation models by dynamical relaxation: an examination of the technique. Quarterly Journal of the Royal Meteorological Society, 103(436): 225-245.

DeAngelis A, Dominguez F, Fan Y, et al. 2010. Evidence of enhanced precipitation due to irrigation over the Great Plains of the United Station. Journal of Geophysical Research, 115(D15): 1-14.

Du H W, Yan H. 1993. A numerical experiment of the influence of underlying surface on a short-range Synoptic process II. Chinese Quarterly Journal of Applied Meteorology, 4(4): 385-393.

Eddy J A, Stidd C K, Fowler W B, et al. 1975. Irrigation increases rainfall? Science, 188(4185): 279-281.

Grell G A, Dudhia J, Satuffer D R. 1994. A description of the Fifth-Generation Penn State/NCAR Mesoscale Model (MM5). In: National Center for Atmospheric Research. NCAR Technical Report Note TN-398. Colorado, USA.

Guo W D, Ma Z G, Yao Y H. 2003. Regional characteristics of soil moisture evolution in Northern China over recent 50 years. Acta Geographica Sinica, 58(suppl.): 83-90. vides favorable dynamic conditions for the formation of precipitation, and precipitation and temperature in non-oasis areas are impacted through sub-level circulation and large-scale advection processes.

Although there are some biases in the simulation of RegCM3 in the arid regions of Xinjiang, the sensitivity experiment reveals that soil moisture has some significant impacts on weather and climate over these regions. The soil moisture abnormality in the early period obviously affected the meteorological elements including precipitation and temperature in the later periods.

\section{Acknowledgments}

This work was supported by the National Natural Science Foundation of China (40875010, 41005050), the Xinjiang Science and Technology Support Project (200891129), and the Global Change National Key Scientific Research Project (2011 CB952002).

Henderson-Sellers A. 1996. Soil moisture: a critical focus for global change studies. Global and Planetary Change, 13(1-4): 3-9.

Holtslag A A M, De Bruijn E I F, Pan H L. 1990. A high resolusion air mass transformation model for short-range weather forecasting. Month Weather Review, 118: 1561-1575.

Kanamitsu M, Ebisuzaki W, Woollen J, et al. 2002. NCEP-DOE AMIP-II Reanalysis (R-2). Bulletin of the American Meteorological Society, 83(11): 1631-1643.

Kiehl J T, Hack J J, Bonan G B, et al. 1993. Description of the NCAR community climate model (CCM3). In: NCAR Technical Report Note TN-464. National Center for Atmospheric Research. Colorado, USA.

Lenters J D, Coe M T, Foley J A. 2000. Surface water balance of the continental Unite States, 1963-1995: regional evaluation of a terrestrial biosphere model and NCEP/NCAR reanalysis. Journal of Geophysical Research, 105(D17): 22393-22425.

Li Q P, Ding Y H, Dong W J. 2007. A numerical study on the effects of the soil moisture upon the regional short-term climate. Journal of Applied Meteorological Science, 18(1): 1-11.

Ma Z G, Fu C B, Xie L, et al. 2001. Some problems in the study on the relationship between soil moisture and climatic change. Advance in Earth Sciences, 16(4): 563-568.

Moore N, Rojstaczer S. 2001. Irrigation-induced rainfall and the Great Plains. Journal of Applied Meteorology, 40(8): 1297-1309.

Namias J. 1958. Persistence of mid-tropospheric circulation between 
adjacent months and seasons. In: The Atmosphere and Sea in Motion (Rossby Memorial Volume). Oxford: Rockefeller Institute Press and Oxford University Press, 240-248.

Namias J. 1963. Surface-atmosphere interactions as fundamental causes of droughts and other climatic fluctuations. In: Symposium on Changes of Climate with Special Reference to Arid Zones. Paris: UNESCO Publication, 20: 345-359.

Pal J S, Eltahir E A, Small E E. 2000. Simulation of regional-scale water and energy budgets: representation of subgrid cloud and precipitation processes within RegCM. Journal of Geophysical Research, 105(D24): 29579-29594.

Roads J O, Chen S C, Kanamitsu M, et al. 1999. Surface water characteristics in NCEP global spectral model and reanalysis. Journal of Geophysical Research, 104(D16): 19307-19327.

Shi Y F, Shen Y P, Hu R J. 2002. Preliminary study on signal, impact and foreground of climatic shift from warm-dry to warm-humid in Northwest China. Chinese Journal of Glaciology and Geocryology, 24(3): 219-226.

Shukla J, Mintz Y. 1982. Influence of land-surface evapotranspiration on Earth's climate. Science, 215(4539): 1498-1501.

Sun C H, Li W J, Zhang Z Q, et al. 2005. Impact of Huaihe River Basin soil temperature and humidity abnormality in pre-winter and spring time on the anomalous summer rainfall and its application. Acta Me- teorologica Sinica, 63(1): 115-121

Walker J, Rowntree P R. 1977. The effect of soil moisture on circulation and rainfall in a tropical model. Quarterly Journal of the Royal Meteorological Society, 103(435): 29-46.

Wang W Q. 1991. Numerical experiments of the soil temperature and moisture anomalies' effects on the short term climate. Chinese Journal of Atmospheric Sciences, 15(5): 115-123.

Xie Z Q, Liu J M, Ding Y G, et al. 2005. Variation features of soil temperature and moisture content at dry- and alpine-desertification surface and their interaction analyse. Plateau Meteorology, 24(1): $16-22$.

Yang L M, Zhang Q Y. 2007. Circulation characteristics of interannual and interdecadal anomalies of summer rainfall in north Xinjiang. Chinese Journal of Geophysics, 50(2): 412-419.

Yeh T C, Wetherald R I, Manabe S. 1984. The effect of soil moisture on the short-term climate and hydrology change: a numerical experiment. Monthly Weather Review, 112(3): 474-490.

Zhang J B, Shi Y G. 2002. The Study on Climate Change and Short-term Climate Prediction in Xinjiang. Beijing: China Meteorological Press, 82-84.

Zhu Q G, Lan H P, Shen T L. 1996. Numerical study of the influence of soil moisture and surface albedo on climate of north part of China. Acta Meteorologica Sinica, 54(4): 493-500. 